\title{
UNA VERSIÓN DEL DRAMA EL TROVADOR, DE A. GARCÍA GUTIÉRREZ: LA NOVELA HOMÓNIMA DE R. ORTEGA Y FRÍAS
}

\author{
Enrique Rubio CREMADES \\ Universidad de Alicante
}

Los juicios emitidos por el propio Larra en su artículo El Trovador. Drama caballeresco, en cinco jornadas, en prosa y verso son reveladores y, en gran medida, sustanciosos por su agudeza y visión tanto de la propia obra como de la dramaturgia española. Tras ponderar los aciertos de García Gutiérrez y especificar que se trata de un escritor hijo del ingenio y de pertenecer a la aristocracia del talento, señala, entre otros aspectos sutilmente analizados, que su autor ha «imaginado un plan vasto, un plan más bien de novela que de drama, y ha inventado una magnífica novela; pero al reducir a los límites estrechos del teatro una concepción demasiado amplia, ha tenido que luchar con la pequeñez del molde» (1836). Valoración del drama que tuvo feliz acogida en R. Ortega y Frías pues trasladó a su novela -El Trovador (1860)- el argumento de dicha obra, complementándolo con secuencias e introduciendo una serie de episodios completamente nuevos que no cercenan en absoluto los caracteres y los motivos o temas esenciales del drama, pese a tratarse de una novela que sobrepasa las quinientas páginas.

R. Ortega y Frías ${ }^{1}$, discípulo aventajado del célebre folletinista Fernández y González, se adentró en la historia de España como por terreno conquistado, pues

1 Entre las obras más leídas figuran sus tempranas novelas Caballero Relámpago (1855), Guzmán el Bueno (1857), El Diablo en Palacio (1857-1858) y Cervantes (1859). Las novelas más famosas fueron El Diablo en Palacio, El tribunal de la sangre o los secretos del Rey (1867), El testamento de un contspirador y Memorias de un reo de Estado (1878). Ortega y Frías se adscribió a la 
la analizó desde su peculiar vista y ofreció sus hechos y personajes históricos de forma no poco sorprendente. Su animadversión por la figura de Felipe II y la Inquisición es evidente en sus novelas, motivada, tal vez, por la influencia del historiador Juan Antonio Llorente ${ }^{2}$. Sin embargo, en el presente caso, en su novela El Trovador, nada de esto ocurre, pues toma casi en su esencia el argumento del drama de García Gutiérrez. Es evidente que no se puede hablar de fuentes literarias o influencias de obras en el relato de Ortega y Frías, pues serían las mismas que en época temprana señaló la crítica a la hora de analizar la obra de García Gutiérrez (Adams 1922). En este sentido cabe señalar las concomitancias con el Macias de Larra y con la novela de A. Dumas Henri III et sa cour o con los relatos de E. Scribe -La Bohémienne- o V. Ducange -La Sorcière-, principalmente. Ortega y Frías se adueña de todo este corpus y se adentra en el drama El Trovador con licencia explícita del propio García Gutiérrez, tal como el mismo novelista señala, a guisa de prólogo, en el inicio de la novela ${ }^{3}$.

novela psicológica, como en sus relatos titulados Las victimas del amor (Estudio del corazón humano) (1882) y Abelardo y Eloisa (1867). No menos célebres fueron sus relatos y libros de viajes y aventuras por la América Hispana, como La Casa de Tócame Roque o un crimen misterioso. Novela histórica original (1877), Vida y viajes de Cristóbal Colón (1873-1874), Conquista de Mejico por Hernán Cortés (1874), Un año entre salvajes. Viajes y aventuras del Doctor Smit (1875) e Islas Maravillosas. Viajes a las regiones del Ecuador. Aventuras del Capitán Bristol. Razas desconocidas, sus pueblos, sus gobiernos, su religión y sus costumbres. El mar azul, el desierto de los tesoros, criaderos de diamantes, las arenas de oro (1882-1883).

${ }^{2}$ En su obra narrativa se percibe la influencia de los estudios debidos a dicho historiador, en especial los dedicados a la Inquisición, como, por ejemplo, Anales de la inquisición en España (18121813) y Memoria histórica sobre cuál ha sido la opinión nacional de España acerca del Tribunal de la Inquisición (1812).

3rtega y Frías reproduce la carta envidada a García Gutiérrez, fechada en Madrid, 23 de octubre de 1859. El texto es el siguiente:

Sr. D. Antonio García Gutiérrez.

Muy señor mío y de mi mayor estimación: no dedico a usted la presente obra, porque no me parece bien dedicarle sus propios pensamientos, es decir, ofrecerle lo que es suyo.

El Trovador es demasiado popular para que yo tenga que advertir que es de V. y no mío; pero sin cmbargo, el consignarlo así es mi deber, lo mismo que el expresar a V. mi agradecimiento por su benevolencia al autorizarme a escribir la presente obra sobre el argumento de la que ha dado a V. un merecido y envidiable renombre, y una joya más al Parnaso español.

Nada he hecho más que añadir a las esplendentes galas de El Trovador, alguna flor, pobre de aroma, que por casualidad brotó en árido campo de mi fantasía: la gloria es de V., si la merece mi obra; pero yo soy responsable de sus defectos.

Ruego a V. acepte la expresión de mis sentimientos como testimonio de la gratitud y distinguida consideración de su afectísimo atento seguro servidor.

Q.B.S.M.

Ramón Ortega y Frías

Madrid 23 de octubre de 1859 
La dependencia, pues, de Ortega y Frías con respecto a García Gutiérrez es más que evidente, aunque no por ello se le puede tachar de poco original, pues introduce numerosos episodios novelescos que no aparecen en el drama. La recreación del contexto histórico es más amplia, al igual que la presencia de nuevos personajes que en el drama sólo se tiene noticia a través de terceras personas. Incluso, como es lógico, adapta nuevos recursos y estrategias narrativas que en un drama eran, prácticamente, imposibles.

El inicio de la novela El Trovador se abre con una amplia estructura titulada Prólogo.-La Gitana, en la que el autor de forma harto generosa recrea parte de lo sucedido en la Jornada I. Cuadro $1^{\circ}$. En el drama, García Gutiérrez se sirve de la narración y perspectiva de Guzmán, Gimeno y Ferrando, criados del conde de Luna, para informar a los espectadores o lectores del drama de lo acaecido en el año 1390: rapto y quema en una hoguera del primogénito del conde don Lope de Artal que a la sazón contaba con dos años de edad. La culpable sería Azucena, hija de Estrella, gitana acusada de bruja y hechicera. Todo lo que sucede se cuenta de forma escueta, concisa, lacónica; sin embargo, en la novela se describirá en tres largos capítulos, revelándose al final del tercero el error cometido por la gitana, pues por equivocación ha dado muerte a su propio hijo y salvado al del conde de $\mathrm{Artal}^{4}$. Revelación de este terrible secreto que en el drama no se produce con tanta celeridad, ya que es necesario llegar hasta la Jornada III, Cuadro $1^{\circ}$ para comprobar lo confuso de la ascendencia del trovador Manrique, pues Azucena le cuenta a su hijo la muerte de su madre en la hoguera y cómo se vengó raptando al hijo del conde y quemándolo posteriormente. Primero dirá que arrojó a la hoguera a su propio hijo y, tras la confusión de Manrique, la gitana lo desmentirá.

El resto de la novela, salvo la tercera estructura -Prólogo-, puede considerarse como una amplia segunda estructura que narra las andanzas y aventuras del trovador Manrique. Esta segunda estructura está ambientada en los albores del siglo XV, durante la guerra entre los pretendientes a la Corona de Aragón. A diferencia del drama, Ortega y Frías no pasa de soslayo antes estos hechos, pues ofrece nuevos datos históricos y recrea sucesos bélicos con los correspondientes nobles que pretendieron la corona del reino de Aragón. En el drama se alude a estos hechos, pero no tienen una intervención decisiva, pues la acción se fundamenta en los amores del trovador Manrique con Leonor, a la que su hermano, Guillermo de Sesé, pretende casar con don Nuño de Artal, noble de la corte arago-

${ }^{4}$ Tras pronunciar la gitana Azucena las terribles palabras dirigidas a su madre difunta « está vengada! ¡Ya está vengada [...] Entonces quiso acariciar a su hijo que lloraba; pero al acercarlo a su rostro para besarlo, su corazón dejó de latir, quiso gritar y no pudo... ¡El niño que tenía en sus brazos era el hijo del conde! Lo que sintió aquella madre infeliz al ver que ella misma había quemado a su hijo, es imposible explicarlo. Su cuerpo vaciló un instante y cayó sin sentido entre la maleza. ¡Desdichada! (1861, pág. 36). 
nesa y rival político del trovador. Los datos cronológicos que figuran en la novela son más copiosos que en el drama. El primer dato se refiere a lo acaecido el 3 de mayo de 1389 y los siguientes guardan interrelación con específicos sucesos históricos sucedidos hasta la muerte de Manrique: la derrota de los pretendientes a la corona de Aragón y el triunfo de don Fernando de Antequeras ${ }^{5}$. La recreación, pues, de los hechos históricos se remonta a la crisis de la Corona de Aragón, en los últimos años del reinado de Martín I el Humano, sin descendencia legítima a quien transmitir el trono, aunque intentó legarlo a su nieto natural don Fadrique de Luna mediante la pertinente legitimación. La promulgación como rey de un descendiente de Martín I por línea ilegítima soliviantó a sus súbditos que, tras deliberaciones harto arduas celebradas en Caspe (1410-1412), designaron rey de Aragón-Compromiso de Caspe- a don Fernando I de Antequera, tío del rey de Castilla. En la novela, al igual que en el drama, los datos y fechas históricas rememoran los enfrentamientos civiles habidos en el reino de Aragón a raíz de la muerte de don Martín el Humano (1410), fallecido, como hemos indicado, sin descendencia directa. Sin embargo, en la novela de Ortega la acción no finaliza en el momento en que se ejecuta a Manrique, sino varios años más tarde.

En toda esta segunda estructura la recreación histórica enmarca y da cobijo a los sentimientos amorosos existentes entre Leonor y Manrique, cuyo rival, el conde de Artal, manifiesta de forma contundente toda su animadversión. El lector percibe con nitidez las formas del típico triángulo amoroso, desde cuyos vértices emanan tanto la pasión y el odio como los celos y la venganza. En el drama de García Gutiérrez el final se produce a raíz de la ejecución y del pronunciamiento de las terribles palabras de la gitana Azucena a don Nuño de Artal. El diálogo no puede ser más terrible ni espantoso:

${ }^{5}$ El primer dato cronológico alude al aniversario del nacimiento de don Lope de Artal (3 de mayo de 1389) y se corresponde con la primera estructura de la novela -Prólogo. La Gitana-. El arranque de la novela, capítulo I, se inicia con precisión histótica, pues su título veinte y dos años después alude a los veintidós años que han transcurridos desde el suceso trágico relacionado con la muerte de don Juan (el trovador Manrique en este contexto histórico), hijo del conde de Artal. Suceso que será recordado con precisión en sucesivos capítulos, como en el titulado De cómo se había cumplido la predicción del cantar del paje. A raiz de este capítulo Ortega alude con precisión cronológica en diversos capítulos para fijar el trasiego novelesco de Manrique, como en los capítulos La trova y Donde se sabrá por conjeturas si el escudero de don Guillén file traidor a la muerte de su señor. En el Epílogo se alude al segundo aniversario de la muerte de Manrique y un año más tarde el lector tiene noticias del arrepentimiento y muerte de don Guillén de Sesé y de don Nuño de Artal, conde de Luna, fallecido este último en el tercer aniversario de la muerte de Manrique. De Azucena nada se sabe con precisión, pues sólo sabemos que vagó durante un tiempo «por las calles de Zaragoza, sin que se le oyese pronunciar una palabra y sin que su mirada sombría se levantase para mirar al cielo, hasta que un día no se encontró más que un cadáver en el mismo sitio donde por tantos años había ardido la hoguera fatal» (1861, pág. 503). 
[...] Azucena: ¡Una palabra, un secreto terrible; haz que suspendan el suplicio un momento!.- - Nuño: No, llevadla. (La toma por la mano y la arrastra hasta la ventana) Ven, mujer infernal... Goza en tu triunfo. Mira el verdugo, y en su mano el hacha que va pronto a caer... (Se oye un golpe, que figura ser el de la cuchilla).- Azucena: ¡Ay! ;Esa sangre!.-- Nuño: Alumbrad a la víctima, alumbradla.- Azucena: ¡Sí, sí... luces! ¡Él es... tu hermano, imbécil!.-- Nuño: ¡Mi hermano! Maldición...! (La arroja al suelo, empujándola con furor).Azucena: ¡Ya estás vengada! (Con un gesto de amargura, y expira) (1985, págs. 197-198).

Sin embargo en la novela de Ortega y Frías este desenlace no se produce de la misma forma, pues introduce una tercera estructura que posibilita la continuación de los hechos y vivencias de los principales personajes que participaron de forma directa en la muerte de los protagonistas: don Nuño de Artal, don Guillermo de Sesé, y el fiel escudero de Manrique, Ruiz. Este último, convertido en devoto y abnegado fraile, asistirá de forma casual como confesor de don Nuño y don Guillermo que, arrepentidos y sumidos en la desolación, entregarán sus almas a Dios. Esta tercera estructura estará marcada por el recuerdo y arrepentimiento, conscientes de ser los principales causantes de las muertes del Trovador y doña Leonor.

La rivalidad amorosa constituye el eje esencial que vertebra la acción, condicionada por diversos sucesos que acrecientan aun más, si cabe, dicha rivalidad. El enfrentamiento se produce y se ofrece al lector desde distintas perspectivas, actuando cada una de ellas como un sumando más a esta cadena de enfrentamientos. Este esencial asunto se engarza con otros que configuran también la obra de Ortega y se complementa en numerosas ocasiones, como el motivo de los celos o el tema de la venganza. En el caso de los celos tanto en la obra de García Gutiérrez como en la de Ortega el lector o espectador tiene ocasión de constatarlo en diversas situaciones. El desasosiego, la inquietud y la duda asoman en el ánimo de Manrique y don Nuño. Así, al final, escena IV, en el encuentro entre Leonor y Manrique, éste manifiesta sus celos ante el importuno rival, don Nuño. Si esto sucede en el drama de García Gutiérrez, otro tanto ocurre en la novela de Ortega, aunque en esta última obra el motivo de los celos y la rivalidad amorosa son mucho más intensos y vehementes. De hecho el enfrentamiento y la rivalidad amorosa se producen en el primer capítulo de la novela y no cesa ni se interrumpe hasta la muerte del propio Manrique. Celos que se dan tanto en don Nuño de Artal como en el Trovador $y$, al igual que en el anterior caso, también de forma temprana. El mismo don Guillén de Sesé, hermano de doña Leonor, le hará ver a don Nuño su condición de celoso enamorado: «Veo, señor conde, que como a todos los enamorados, los celos no os dejan completamente libre el juicio; porque a no ser así ¿cómo habíais de dar crédito a las hablillas del vulgo y a la murmu- 
ración de los cortesanos? -No son hablillas, porque el Trovador entona muchas noches sentidos romances» (1860, pág. 55). Si esto sucede en don Nuño, otro tanto acaece en Manrique, que, preso de los celos, lleva una penosa existencia, tal como se percibe en el diálogo que el fiel criado, Ruiz, y Manrique mantienen: «Necesito matar al conde o que me mate para no sufrir lo que sufro. ;Oh!... No sabes lo que son los celos...- No quiera Dios, porque a vos os han puesto amarillo y aun algo más flaco [...]» (Ibíd., pág. 97). Con igual pujanza y reiteración aparece en la novela el tema de la venganza, pues su desarrollo es continuo y su persistencia harto singular. Tanto en la novela de Ortega como en el drama de García Gutiérrez, la gitana Azucena sólo puede esgrimir la venganza como arma arrojadiza y contrapunto del poder. Frente al poder, Azucena se sirve del odio y de la venganza para combatir contra los agravios cometidos por el conde de Luna y sus acólitos. La muerte de su madre, la gitana Estrella, será el principal motivo que alimente sus ansias de venganza. Madre e hija claman venganza como única vía posible de luchar contra la injusticia, de ahí que dicha palabra aparezca tanto en el inicio como en el final de ambas obras?.

En la novela de Ortega y Frías aparecen múltiples recursos propios de la novela histórica y del folletín. Técnicas narrativas que posibilitaban una acción trepidante, plagada de aventuras y sobresaltos. El mundo de ficción será el

"Desde la perspectiva del narrador y de los protagonistas también se ofrece al lector el daño y furor que causan los celos de Manrique: «El mancebo sufría mucho también porque amaba a Leonor con todo el ardimiento de quien no ha sentido afecciones y en una sola se reconcentran los gérmenes todos de su ternura [...] Pero como es tan exigente el amor y tan descontentadizos los celos, se atrevió todavía Manrique a decir [...]» (1861, pág. 120). Más adelante se referirá de nuevo a los celos: « ¿No pensáis, desdichada [Leonor], que encendéis más el enojo de mis celos, y aumentáis mi sed abrasadora de venganza?» (1861, pág. 438).

Celos que también hacen mella en el rival amoroso del Trovador, el conde de Luna, pues desde el inicio mismo de la novela hasta el final de la misma, los celos configuran la conducta de dicho personaje: «El conde de Luna, seguido de algunos soldados, entró en la prisión. Su rostro estaba contraído y su mirada era sombría. La tardanza de Leonor le hizo sospechar que ésta, no pudiendo conseguir otra cosa, había querido despedirse de su amante.- ¡Leonor! -gritó con voz ahogada por el coraje de los celos [...]» (1861, pág. 451).

${ }^{7}$ Precisamente, el primer grabado, de los muchos que se encartan en la novela, alude a la quema en la hoguera de la gitana Estrella en presencia de su hija Azucena y con un pie de página que dice lo siguiente: « ¿éngame! ¡Maldita seas si no tienes valor para vengarme!». Frase cuya continuación en la novela es repetitiva y harto elocuente, pues regirá el destino y los lances de los principales personajes de la trama. Las patéticas palabras de la madre formuladas en la hoguera, quedarán grabadas para siempre en la joven Azucena: «Las llamas prendieron en los harapos de la infeliz, y como una columna de fuego, se la veía girar y agitarse mientras que sus ojos parecían que se iban a salir de sus órbitas, y su áspera cabellera flotaba entre el humo ¡véngame! -gritaba con acento desgarrador que se repetía cien veces en la montaña. Y los escuderos reian más y más -jMira como baila! --decian los unos.- ¡Mal huele la maldita! -añadían los otros - Te vengaré, madre mía -exclanaba Azucena -;Véngame! -repetía sin cesar su madre. Y crecieron las llamas, y no se vio otra cosa que los cabellos de la víctima, pero se oyeron sus gritos pidiendo venganza) (1861, pág. 22). 
mismo que el ideado por García Gutiérrez, sin embargo, en Ortega y Frías, sus personajes, tanto los pertenecientes al contexto real de la historia de Aragón y Castilla, como los engarzados con la tradición -Manrique y Leonor- vivirán numerosas aventuras y lances que serán producto de la imaginación del propio novelista. De esta manera el peculiar subjetivismo de Ortega para interpretar la historia hará posible que la totalidad de sus personajes se enmarquen en la clásica dualidad propia del folletín. El lector, pues, puede percibir con claridad la división de un mundo de ficción configurado por personajes cuya conducta es completamente distinta a la de los héroes con un alto concepto del honor. No existe el justo medio entre las facciones políticas enemistadas, pues frente a los personajes dadivosos, entregados desinteresadamente a una causa y de una conducta intachable aparecen otros cuyos actos nacen de la envidia y perversión. Así, Manrique, alférez y favorito del conde de Haro, estará al servicio de la causa de dicho personaje, de tal suerte que ambos, pese a perder la contienda, y, por ende, los derechos del Conde de Haro a la corona de Aragón, serán los prototipos de la generosidad, caballerosidad, honradez y pundonor. Frente a ellos, los personajes malévolos, perversos, indignos y sin pundonor, como Lope de Urgel, Lope Gutiérrez, Guillén de Sesé y el conde de Luna, todos servidores y defensores del Infante don Fernando, pretendiente también a la corona de Aragón. La novela de Ortega recrea con toda suerte de detalles las rivalidades cortesanas y las intrigas palacicgas de los pretendientes al trono. Es evidente que los aragoneses aparecen en la novela como seres provistos de un alto concepto del honor, combativos y entregados a su causa con total desinterés. Son excelentes patriotas que no piden nada a cambio. Por el contrario, el bando castellano está plagado de intrigantes, de personajes malévolos y traidores arrivistas que sólo dan su apoyo a cambio de pingües beneficios. Intentan medrar a costa de cualquier precio. El infante don Fernando, rival del conde de Haro y, por ende, enemigo también del Trovador, será descrito con tonalidades asaz negativas ${ }^{8}$. Los representantes y defensores de esta facción se servirán de la traición como única arma para vencer a sus contrincantes y adversarios. Incluso, algunos de estos personajes, como el rival amoroso de Manrique, el conde de Luna, utilizarán todas las tretas y argucias posibles con

* Al final de la novela el propio Ortega y Frías concretiza el comportamiento de don Fernando una vez cumplido su propósito: la corona de Aragón. El comportamiento de don Fernando raya en el deshonor a tenor de lo descrito en la novela: «El triunfo de don Fernando había sido completo. Ya no tenía quien le disputase la corona, y podia dejar el disimulo con que hasta entonces habia cubierto sus inclinaciones despóticas y sus instintos ambiciosos y crueles. Muchos caballeros del bando del de Urgel salieron del reino, temerosos de la saña del rey, porque no había inspirado la mayor contianza el perdón otorgado [... . La venganza de don Fernando fue más cruel aún, porque tambićn persiguió a lá anciana madre del conde, sin que ésta hubiese cometido otra falta que la de acudir al rey de Portugal [...] ]» (1861, págs. 498-499). 
tal de conseguir sus propósitos. Siempre de forma traidora. El mismo Manrique le reprochará sus maldades y ruines traiciones; primero, por asesinar al obispo de Zaragoza; más tarde por faltar a su juramento de defender los intereses de Aragón y, por último, por renegar de su patria?

Manrique, al igual que otros héroes propios de las novelas históricas del romanticismo, es el verdadero adalid de la justicia y del honor. Él es el prototipo de héroe generoso, apasionado, cuya actitud contrasta con la de sus rivales, empeñados en acabar con su existencia por ser un férreo bastión de los intereses del conde de Haro y, por ende, del pretendiente don Jaime, el Desdichado. En esta galería de personajes infames, inmorales y aviesos destaca Lope Gutiérrez, confidente de don Nuño y del infante castellano don Fernando. En el inicio de la novela aparecerá como fiel servidor del pretendiente don Jaime, principal valedor de Manrique. Sin embargo, con el correr de los hechos el lector percibirá con nitidez que se trata de un traidor, de un espía que está al servicio del infante castellano. Don Lope Gutiérrez es el prototipo de la vileza, ruindad, tunantería y servilismo. Él es un eslabón más del bando castellano, su representante más significativo ${ }^{10}$. Ortega y Frías se sirve de don Lope para denunciar las mezquindades del infante don Fernando, pues utilizará todas las argucias, a cual más mezquina, para conseguir la corona de Aragón. Frente a la ignominia, el deshonor y la abyección surge Manrique, el Trovador, descrito siempre con los atributos del caballero con honor, decoro y caballerosidad, pese a ser hijo de una gitana. Su porte, ademanes y su pundonor los resalta Ortega desde el inicio de la novela.

"El capítulo XLI, De la entrevista de Manrique y don Nuño, es un fiel exponente de las maldades, perversiones y traiciones de don Nuño de Artal que, además de cometer las infamias ya referidas, es acusado por el propio Manrique de la siguiente guisa: «Vendisteis vuestro brazo, vuestros derechos, a vuestra patria... Eso hicisteis, don Nuño de Artal, ilustre conde de Luna, descendiente de cien nobles godos, vendisteis vuestra honra con menos vergüenza de la que tiene un pobre villano cuando el hambre le obliga a vender su vestido» (1861, pág. 416).

${ }^{10}$ Ortega y Frías lo describe desde múltiples ópticas, todas asaz negativas. Él será el culpable de todas las derrotas sufridas en el bando del Trovador. Sus mentiras y su astucia para confundir al ejército de don Jaime, el Desdichado, posibilitan su rendición y pérdida de sus bienes. Ortega lo presenta siempre de esta guisa: «El plan era digno de don Lope, y daba una cabal idea de su miserable ruindad; pero ni el conde, ni don Guillén mostraron escrúpulos, su sed de venganza daba por bueno todo lo que pudiera satisfacerla [...] Más que a vos me atormenta el deseo de vengarme, replicó don Lope cuyos ojos relumbraron por un instante [...]» (1861, pág. 376).

La traición será siempre para don Lope la única arma capaz de vencer cualquier situación, como en el texto que a continuación ofrecemos y en el que los protagonistas son don Nuño, don Guillén y el propio don Lope: «Bien conozco cuán difícil, casi imposible es vencer al Trovador, lo confieso con vergüenza, pero no me siento con valor para prepararle a sangre fría una emboscada.Aprensiones, dijo el hidalgo encogiéndose de hombros: tales son todas las cosas del mundo y muy particularmente lo que llaman leyes del honor. ¿Cómo triunfamos en Murviedro? Con un engaño, una traición. ¿Cómo habéis vencido en más de una batalla? Engañando al enemigo, preparándole a sangre fría una emboscada [...]» (1861, pág. 375). 
Desde un primer momento aparece como un hombre valeroso, aguerrido, astuto ante el enemigo, de gran corazón, altivo cuando lo requiere la ocasión, arrogante ante quienes detentan el poder, feroz guerrero en la contienda, amante apasionado, bueno en el sentido estricto de la palabra. Sus hechos no conocen barreras, ni tienen límites. Lo mismo declara ser hijo de una gitana sin sentir vergüenza alguna, que ultraja, acusa y humilla a la nobleza o realeza que actúa con deshonor. Intrépido hasta rayar en lo temerario. Sus incursiones, tanto en palacio como en el convento, rodeado de espías y enemigos sañudos, serán fiel exponente de su valor, intrepidez y temeridad. Hombre con temple y bizarro capaz del sacrificio. No desdeña la muerte, pero tampoco la teme. Furia, ardor y espíritu en todos sus hechos. Manrique es, en definitiva, un hombre de honor, el principal eslabón de esa facción de personajes generosos, virtuosos y sensibles que dan vida al bando antónimo de la perversión. División del mundo novelesco que no difiere al de relatos publicados en el Romanticismo, como en las clásicas novelas $E l$ doncel de don Enrique el Doliente, Sancho Saldaña o El señor de Bembibre ${ }^{1 !}$.

Los recursos del folletín y la parcial reconstrucción de la historia configuran el armazón de la novela. A la ya clásica división del mundo de ficción habría que añadir otros de ilustre tradición en el género, como, por ejemplo: descripciones propias de las novelas góticas ${ }^{12}$, situaciones misteriosas ${ }^{13}$, orígenes incier-

${ }^{11}$ Recordemos, por ejemplo, la facción intrigante y malévola de El doncel de don Enrique el Doliente: el marqués de Villena, Ferrús, Abenzasal... En la otra facción, los personajes con un alto concepto del honor, como en el caso del propio Macías o el buen Hernando. Otro tanto sucede en Sancho Saldaña gracias a las rivalidades entre el propio Sancho y Hernando o entre Jimeno y Usdróbal. En El señor de Bembibre las facciones estarán perfectamente delimitadas, siendo la conducta del conde de Lemus totalmente opuesta a la de don Álvaro. Las facciones que ambos representan son irreconciliables. Sólo la muerte puede poner fin a tales rivalidades. Es, pues, el mundo antagónico lo que posibilita esta clara división del mundo novelesco, al igual que en numerosas novelas seudohistórico-folletinescas de mediados del siglo XIX.

${ }_{12}$ En la novela de Ortega aparecen numerosas secuencias propias de la novela gótica o de terror. Truenos, rayos, misteriosas apariciones, llantos y gritos misteriosos, pasadizos secretos, convulsiones, etc. Por ejemplo, la descripción de un castillo o convento medieval suele estar descrito de esta forma: «Aquella noche no se ó́a el murmullo de las fuentes, ni los trinos del ruiseñor, el canto lúgubre de la lechuza, el tableteo del trueno y el bramido del huracán eran los únicos ruidos que se oían [...] Seguian esparciendo los relámpagos sus pasajeros fulgores, dejando ver por un segundo los capiteles y los árboles como fantasmas envueltos en túnicas de azulado fuego [...] Un trueno resonó, propagándose más que el de ninguno de sus ecos espantables. Algunos segundos después saltó Manrique al interior de la celda. Su corazón palpitaba como si fuese a romperse. Su rostro estaba descompuesto [...]) (1861, pp. 283-284).

13 Proliferación también de situaciones misteriosas a fin de acrecentar la emoción 0 , simplemente, la incertidumbre en el lector. Se trata, al igual que en el anterior, de uno de los recursos más utilizados por los novelistas adscritos a esta modalidad literaria. La frecuencia de embozados, espías secretos, personajes de personalidad cambiante, entre otros aspectos, suele ser frecuente en el relato de Ortega y Frías. V. gr.: «Satisfecho iba el hidalgo de la entrevista, pero se acibaró su contento al salir de la calle y ver un embozado que le siguió [...] Aunque la oscuridad de la noche, que ya había 


\section{$\operatorname{tos}^{14}$, objetos o prendas que hacen posible que su portador pueda acceder a los lugares más increíbles o entrevistarse con los personajes más insospechados ${ }^{15}$.}

cerrado no permitía distinguir bien los objetos [...] y siguió sin dirección fija, tomando, ya a la derecha, ya a la izquierda, y observando si el embozado iba tras él» (1861, pp. 149-150). Más adelante se repetirán en varias ocasiones esta misma situación: «iVeis aquellos dos bultos? -respondió el sirviente, señalando al extremo de la calle.-Sí- Pues son dos hombres que hace buen rato pasan y repasan, me miran y observan con disimulo» (1861, pp. 248-249). Bultos, encapuchados, personas de siniestra mirada, etc. suelen ser frecuentes en la novela a fin de conseguir ese hálito misterioso tan característico de las novelas históricas y seudofolletinescas En los capitulos «Donde veremos si cran acertadas las sospechas del Trovador», «Burla por burla», «La Trova», «Por la ventana y por la puerta», «Donde se prosiguen los sucesos relativos al de Urgel» y «De cómo el conde facilitó a Manrique la entrada en el conventoy este tipo de situaciones es harto frecuente.

1.4 El origen incierto cobra especial relevancia durante la época romántica. En este sentido, Ortega y Frías sigue los modelos clásicos del género e introduce este trascendental rasgo en su mundo de ficción. Las interrogantes sobre la ascendencia y linaje de los personajes suelen poblar las páginas de la novela. He aquí uno de los numerosos ejemplos: «»-jY me retáis!... Enferma debe estar vuestra razón. --¡Don Nuño!- volvió a decir Manrique, clavando en el conde una terrible mirada. - ¿Cómo os llamáis? Acaso mi acero puede medirse con el de un hombre oscuro, sin nombre, sin patria?... Pensadlo bien, don Manrique» (1861, p. 101). Manrique será desde la perspectiva del bando rival un trovador oscuro y miserable. Su orfandad y misterioso nacimiento impresionarán vivamente a los seres más queridos por Manrique, como en el caso de su amada Leonor cuando conoce el origen incierto del Trovador en el capitulo "Consecuencias de la batalla».

${ }^{15}$ Objetos, señales o prendas cuya pertenencia a una persona podrá permitir el acceso a los lugares más insospechados. El objeto permite a su portador evitar los peligrosos controles y entrevistarse hasta con la propia realeza. Incluso, un lunar o una peculiar mancha en la piel servirá también para identificar a un individuo, como se aprecia, por ejemplo, en el capitulo «Del resultado que tuvo el desafio de dos hermanos»: «Esto es horrible y debo evitarlo, porque revelar a Manrique el secreto de su nacimiento después que haya vertido la sangre de su hermano, sería hacerle morir atormentado por los remordimientos. Don Nuño perderá una corona, y tal vez la vanidad y el ruin interés le hagan poner en duda que Manrique es su hermano, pero yo desnudaré la espalda del que pronto será conde, y haré ver el lunar negro con cabellos rubios de los primogénitos de la familia» (1861, p. 108).

Los objetos se erigen en auténticos protagonistas. Como, por ejemplo, en el capitulo «Desacierto de don Lope», pues el objeto, en este caso un anillo, posibilita toda una serie de enredos propios de una comedia lopesca: «El mancebo le entregará un anillo que es la contraseña, y ella le introducirá, guiándolo a obscuras por el estrecho pasillo que hay a la derecha- Todo lo comprendo: mis soldados se echarán sobre él...(1861, p. 167). A partir de este preciso momento el anillo será el principal referente de varios capítulos, al igual que el objeto que actúa como testigo mudo de las muertes de los principales protagonistas de la novela: la cruz de diamantes de Leonor. Dicho objeto ságrado caerá en manos del fiel escudero de Manrique que, convertido en fraile, dará a besar a los moribundos antagonistas de la novela: don Guillén de Sesé y el conde de Artal. Precisamente, la novela finaliza de esta guisa: «Sí... se muere el señor conde... -¡El Conde!-¡Por Dios.... Venid... Pide confesión--- ¿Le negaréis la confesión? El fraile levantó al cielo los ojos y exclamó con voz ahogada -iDios mío» [...] Pocos minutos después entraba el capuchino en el aposento del conde. Éste confesó, y como don Guillén, besó la cruz de diamantes, recibió la absolución y expiró. El fraile, que era Ruiz, salió del castillo con el rostro bañado en llanto. -iDios mío!- exclamó con voz ahogada-- ¡Cuán grande es vuestra justicia y vuestra misericordia! --El Conde y don Guillén habian sido perdonados por el hombre en nombre de Leonor y Manrique, y por el sacerdote en nombre de Dios) (1861, pp. 506-507). 
Cúmulos casuísticos que dan a la novela un claro tono de inverosimilitud, aunque gane en movilidad y acción, como los encuentros fortuitos de los dos rivales amorosos en el convento de Belén, lugar en el que está encerrada doña Leonor. No menos fortuitas serán las fechas de nacimiento del hijo de la gitana Azucena y del hijo del conde Artal. Ambos nacen en el mismo día, año y hora. Otro tanto ocurre con diversos encuentros protagonizados por personajes cuya importancia es fundamental en los hechos finales de la novela, como el encuentro casual en Zaragoza entre la propia Leonor y Azucena. El misterio o suspense también se produce de forma reiterativa en El Trovador de Ortega y Frías. La forma de utilizar dicho recurso no difiere en nada a la de novelas publicadas en la etapa áurea de la novela histórica y del folletín, pues se vale de la ruptura de la acción en el instante en el que el lector espera la revelación de un misterioso secreto. Mediante la ruptura del momento justo que precede al clímax, Ortega y Frías introduce una nueva secuencia que nada tiene que ver con la anterior. Es, en cierto modo, el recurso fundamental de la novela por entregas, aunque a diferencia de ésta, la solución o la revelación del misterio se encuentra en los siguientes capítulos de la novela, sin necesidad de esperar la ansiada entrega.

El Trovador de Ortega y Frías hace gala de todos estos recursos. No escatima su utilización, de ahí que a los ya apuntados aparezcan otros de fácil identificación y arraigo literarios, pues todos proceden de escritores adscritos a la novela histórico-folletinesca. Por ello es por lo que nos encontramos con personajes embozados, pócimas venenosas, llantos misteriosos, personajes con convulsiones, risas sardónicas, rechinar de dientes, aposentos lóbregos, truenos, rayos, desmayos... Toda una galería de situaciones a fin de provocar las sensaciones deseadas por el escritor. El misterio, las premoniciones y la incertidumbre de los héroes ante peligros inminentes provocan en el lector un estado de ansiedad a sabiendas que el fatum, el destino trágico de los amantes, pondrá punto final al relato. La premonición se filtra a lo largo del relato. Azucena desvela al lector mediante presagios el fatal destino de Manrique, el Trovador. Sus visiones e interpretación de cambios climáticos $u$ objetos que rodean a una determinada persona sirven para augurar un aciago y desventurado final.

Ortega y Frías, pese a seguir en líneas generales las aventuras y desventuras de El Trovador de García Gutiérrez, incluye nuevos episodios que, evidentemente, no podían ajustarse o recrearse en el drama. Enclaves geográficos que tuvieran una gran incidencia en los acontecimientos históricos referidos a la historia de Aragón en el siglo XV, periodo comprendido entre los años 1411 y 1412. Los enfrentamientos civiles que ensangrentaron el reino de Aragón a la muerte de Martín I el Humano son descritos por el novelista con toda suerte de detalles, especialmente los llevados a cabo entre el infante don Fernando y don Jaime de Urgel. Este último, desde el punto de vista jurídico, el pretendiente con más dere- 
chos a la corona de Aragón. Precisamente, el Trovador, será fiel seguidor, como se ha indicado con anterioridad, de su causa, ejerciendo su valía con pundonor y arrojo inusual. Las descripciones de las contiendas se encartan en la peripecia argumental con no poca prodigalidad. De esta forma el lector asiste a los continuos enfrentamientos habidos en este periodo histórico desde el inicio al final, hasta la victoria del infante don Fernando. Escenas truculentas que en nada envidian a aquellos relatos macabros que tuvieron su esplendor en el primer tercio del siglo XIX. Campos sembrados de cadáveres mutilados, escenas dantescas que ocupan capítulos enteros, como el concerniente a la batalla que tuvo lugar en el campo de Murviedro:

Como dos montañas de acero, chocaron ambos ejércitos al encontrarse. Una nube de polvo los envolvió. Resonó un espantable estruendo de clarines, voces y armas, y bien pronto la sangre empezó a correr. Viéronse muchos caballos sin jinetes. Oyéronse amenazas horribles contestadas por lamentos de agonía. Crujieron huesos, rodaron cabezas, saltaron hechas mil pedazos armas y armaduras. Perdía la vida el que acababa de quitarla. Era aplastado por un caballo el que antes había pisoteado a un moribundo. No podía fijarse en lugar alguno la planta sin que se tiñese en sangre» (pág. 316).

Las distintas facciones se enfrentan con virulencia y en ambos lados aparecen los adalides al frente de sus ejércitos. A diferencia del drama, Ortega recrea los enfrentamientos recogidos en las crónicas, pues engarza las luchas con los lugares geográficos en donde tuvieron lugar las respectivas batallas que dieron como vencedor al infante don Fernando.

Ortega y Frías se permite ciertas licencias con respecto al tratamiento que García Gutiérrez da a su héroe principal, como en los hechos recién referidos. La animadversión y el odio entre Leonor y su hermano, don Guillén de Sesé, son mucho más profundas en la novela que en el drama, al igual que las continuas apariciones de la gitana Azucena en los momentos culminantes de la novela. Su omnipresencia posibilita la pervivencia del odio y su sed de venganza. Su locura o demencia está mucho más acentuada que en el drama, aunque sus sentimientos respecto a Manrique son idénticos. Como hemos señalado con anterioridad, la tercera estructura, Epílogo, no existe en el drama. Es aquí, precisamente, donde el novelista dista más del texto de García Gutiérrez, pues ofrece cumplidas noticias sobre el destino de los principales personajes. El conde de Artal y don Guillén de Sesé morirán al poco tiempo abatidos por el remordimiento. Azucena fallecerá al poco de expirar doña Leonor y el Trovador. Aldonza y Ruiz, fieles servidores de los protagonistas, profesarán en una orden religiosa. Serán los únicos supervivientes de un drama que cumple a la perfección el canon y el modelo de la literatura romántica. Una novela cuyo eje esencial es la relación amorosa entre unos amantes infortunados, y que, sin embargo, no desdeña otras líneas o accio- 
nes paralelas a la principal. Acciones paralelas, que como señala Russel P. Sebold (2002, pág.46), «se desarrollan independientes hasta converger».

Finalmente, cabe señalar una serie de aspectos tratados por Ortega y Frías que difieren al de García Gutiérrez. Cambios apenas perceptibles en su esencia y que no inciden para nada en el desenlace final de los amantes. Sería el caso de la utilización del perspectivismo para analizar el comportamiento de los principales héroes del relato. Desde la peculiar perspectiva de los distintos personajes de la novela el lector tiene una completa visión e información de los protagonistas, aunque dicha visión esté realizada de forma sesgada. El narrador se implica también en los hechos al ofrecer al lector una veraz y parcial visión de los sucesos acaecidos. Una novela que a pesar de sus defectos se lee con cierta complacencia gracias a la hábil utilización de los recursos narrativos y ritmo de la acción. Ortega y Frías se desenvuelve con soltura y destreza en la novela histórica de aventuras. El pulso narrativo, su imaginario y la disposición del mundo de ficción hacen posible que su novela, al igual que el resto de su producción narrativa, fuese leída con fervor por un específico tipo de lector ansioso y deseador de intrépidas aventuras amorosas y caballerescas. 


\section{BIBLIOGRAFÍA}

ADAMS, Nicholsom B., 1922. The Romantic Dramas of Garcia Gutierrez, Nueva York, Instituto de las Españas.

LARra, Mariano José de, 4 y 5 de marzo de1836. «El Trovador. Drama caballeresco, en cinco jornadas y en verso», El Español.

LLORENTE, Juan Antonio, 1812. Memoria histórica sobre cuál ha sido la opinión nacional de España acerca del Tribunal de la Inquisición, Madrid, Sancha. 1812-1813. Anales de la Inquisición en España, Madrid, Ibarra.

ORTEGA Y FRÍAS, Ramón, 1885. Caballero Relámpago, Madrid, Imprenta M. González.

1857. Guzmán el Bueno, Madrid, Imprenta de J. Cammoranelly.

1857-1858. El Diablo en Palacio, Madrid, Imprenta de A. Gracia y Orga.

1859. Cervantes. Novela, Madrid, Mariano C. y Gómez, Editor.

1860. El Trovador, Madrid, Establecimiento Tipográfico de Manini hermanos.

1867. El Tribunal de la sangre o los secretos del Rey, Madrid, Imprenta de la Galería Literaria.

1867. Abelardo y Eloísa, Barcelona, Maucci.

1873-1874. Vida y viajes de Cristóbal Colón, Murcia y Martí.

1874. Conquista de Méjico por Hernán Cortés, Madrid, Imprenta de la Galería Literaria.

1875. Un año entre salvajes. Viajes y aventuras del Doctor Smit, Madrid, Librería Anlló y Rodríguez.

1877. La Casa de Tócame Roque o un crimen misterioso. Novela histórica original, Madrid, Murcia y Martí.

1878. El testamento de un conspirador y Memorias de un reo de Estado, Madrid, Saturnino Calleja.

1882. Las víctimas del amor (Estudio del corazón humano), Madrid, Viuda de Rodríguez.

1882-1883. Islas Maravillosas. Viajes a las regiones del Ecuador. Aventuras del Capitán Bristol. Razas desconocidas, sus pueblos, sus gobiernos, su religión y sus costumbres. El mar azul, el desierto de los tesoros, criaderos de diamantes, las arenas de oro, Madrid, Viuda de Rodríguez, editor.

Ruiz Silva, Carlos (ed.), 1985. Antonio García Gutiérrez. El Trovador, Madrid, Cátedra.

SEBOLD, Russell P., 2002. La novela romántica en España. Entre libro de caballerías y novela moderna, Salamanca, Ediciones Universidad de Salamanca. 